\title{
Discurso pedagógico e fracasso escolar
}

\author{
Magda Floriana Damiani
}

\section{Resumo}

Este trabalho apresenta os resultados de uma investigação que, em sua primeira parte, identificou os fatores de risco para fracasso escolar (entendido como repetência e/ou evasão) em uma coorte formada por todas as crianças nascidas nos hospitais da cidade de Pelotas (RS), em 1982. Isto foi levado a cabo por meio de um modelo multivariado que examinou o risco de fracasso associado a diferentes variáveis pessoais e familiares das crianças. Os resultados confirmam os encontrados em outras pesquisas, indicando a importante influência de fatores como grupo étnico, renda familiar, número de irmãos, escolaridade dos pais, tipo de moradia, entre outros, sobre o desempenho das crianças. A segunda parte do trabalho relata estudos de caso de duas escolas (que atendem populações com os mesmos fatores de risco) cujas taxas de reprovação e evasão eram contrastantes (altas em uma escola e baixas na outra). Os resultados indicam que as instituições de ensino diferem entre si e apontam para a importância de fatores intra-escolares, em especial o discurso pedagógico das escolas (conceito definido por Bernstein), para o desempe- nho das crianças. A ênfase nos aspectos acadêmicos da escolarização (discurso instrucional), verificada na escola com menores taxas de reprovação e evasão, possibilitou a modificação de uma das importantes correlações, encontrada também em outras pesquisas, entre fracasso escolar dos estudantes e baixo nível de escolarização de seus pais. A escola que apresentava maiores taxas de fracasso era caracterizada por um discurso pedagógico regulativo (assistencialista).

Palavras-chave: Fracasso escolar. Fatores extra-escolares. Fatores intra-escolares. Discurso pedagógico. Cultura escolar.

Abstract Pedagogic discourse and academic failure

This paper presents the findings of an investigation which, in its first part, identified risk factors for school failure (understood as grade retention and/or drop-out) in a cohort of all children born in the city Pelotas (RS) hospitals, in 1982. This was accomplished through a multivariate model which examined the 
risk for failure associated to children's personal and family variables. The results confirm findings from other research, suggesting the important influence exerted by factors such as ethnic group, family income, number of siblings, parents' level of schooling, type of dwelling, among others, over children's academic attainment. The second part of the investigation reports case studies of two schools (attended by populations that presented the same risk factors) with contrasting rates of repetition and dropout among their students (high in one and low in the other). The results indicate that the institutions differ among themselves and point out to the importance of intra-school factors, especially schools' pedagogic discourse (concept defined by Bernstein) for children's attainment. The emphasis on the academic aspect of schooling (instructional discourse), observed in the school that presented lower failure rates, enabled an effect modification over the important correlation (encountered in other research) between children's failure and parents' low level of schooling. The school which presented the highest rates of failure was characterized by a regulative discourse.

Keywords: School failure. Extra-school factors. Intra-school factors. Pedagogic discourse. School culture.

\section{Resumen \\ Discurso pedagógico y fracaso escolar}

Este trabajo presenta los resultados de una investigación que, en su primera parte, identificó los factores de riesgo para el fracaso escolar (entendido como reprobación y/o evasión) en una cohorte de los niños nacidos en los hospitales de la ciudad de Pelotas (RS), en 1982. Esos factores de riesgo fueron identificados por medio de un modelo multi variado que examinó el riesgo del fracaso asociado a diferentes variables personales y familiares de los niños. Estos resultados confirman los encontrados en otras investigaciones, indicando la importante influencia de factores como grupo étnico, renta familiar, número de hermanos, escolaridad de los padres, tipo de vivienda, entre otros, sobre el desempeño de los niños. La segunda parte del trabajo relata estudios de caso de dos escuelas (que atienden poblaciones con los mismos factores de riesgo) cuyas tasas de reprobación y evasión eran contrastantes (altas en una escuela y bajas en otra). Los resultados apuntan a que las instituciones de enseñanza difieren entre sí y también a la importancia de factores intraescolares, en especial el discurso pedagógico de las escuelas (concepto definido por Bernstein), para el desempeño de los niños. El énfasis en los aspectos académicos de la escolarización (discurso instruccional), verificado en la escuela con menores tasas de reprobación y evasión, posibilitó el cambio de una de las importantes correlaciones, encontrada también en otras investigaciones, entre fracaso escolar de los estudiantes y bajo nivel de escolarización de sus padres. La escuela que presentaba mayores tasas de fracaso era caracterizada por un discurso pedagógico regulativo (asistencialista).

Palabras clave: Fracaso escolar. Factores extraescolares. Factores intraescolares. Discurso pedagógico. Cultura escolar. 


\section{Introdução}

Este trabalho tem como objetivo contribuir para a discussão sobre o fracasso escolar, conceito aqui definido como presença de, pelo menos um episódio de reprovação e/ou evasão na vida das crianças. A pesquisa foi realizada com base em dados coletados entre estudantes do Ensino Fundamental da cidade de Pelotas (Rio Grande do Sul) e constou de duas etapas: um estudo de correlação entre fracasso escolar e variáveis pessoais e familiares dos integrantes de uma coorte composta por todas as crianças nascidas nos hospitais da cidade, em 1982; e estudos de caso de duas escolas, da mesma cidade, que apresentavam índices de fracasso escolar contrastantes (alto e baixo), apesar de atenderem populações semelhantes em termos dos fatores de risco para fracasso apresentados ${ }^{1}$.

trabalho ilustra a importância de entender os processos intra-escolares que estão associados ao desempenho dos estudantes, por meio de investigações de caráter qualitativo, embora reconheça a relevância da contribuição dos estudos quantitativos, voltados à identificação de fatores de risco pessoais e familiares para fracasso escolar, pois estes são indispensáveis para o mapeamento do fenômeno no nível populacional. A investigação sugere que o processo de escolarização não é uniforme em todas as instituições de ensino e que o rendimento acadêmico dos estudantes está fortemente associado a características da cultura ${ }^{2}$ desenvolvida em cada uma delas, associação essa que pode, inclusive, modificar as correlações estatísticas existentes entre fracasso e determinadas características pessoais e familiares dos estudantes - encontradas não somente no Brasil, mas em outros países.

A temática enfocada pela primeira parte do estudo vem sendo abordada há várias décadas, e muito se tem feito para combater o fracasso escolar. Entretanto, ainda contabilizamos percentuais de distorção idade/série iguais a 33,3\% e 40,6\%, respectivamente, para a $4^{a}$. e a $8^{a}$. série do Ensino Fundamental, e igual a 45,9\% para - Ensino Médio (SAEB 2004) em nosso país, acarretando desperdícios de recursos e vagas escolares, além de desgaste pessoal para estudantes e professores. Assim, acredita-se que $o$ assunto continua a merecer nossa atenção de pesquisadores.

\section{Fatores de risco extra- escolares em Pelotas}

As correlações entre desempenho acadêmico e variáveis pessoais e familiares dos estudantes estão muito bem documentadas, tanto no Brasil como em outros países ${ }^{3}$. O quarto acompanhamento do "Estudo Longitudinal das Crianças Nascidas em Pelotas em 1982" (VICTORA; BARROS;

\footnotetext{
${ }^{1}$ A investigação resultou na obtenção do grau de Doutora em Educação pela Universidade de Londres, Inglaterra, em 1998, com apoio do CNPq (DAMIANI, 1998) e nunca foi publicada no Brasil. Uma versão resumida do trabalho pode ser encontrada em (DAMIANI, 1999).

${ }^{2}$ A palavra cultura é aqui empregada como "modo de vida" de uma instituição, incluindo seus códigos de conduta, linguagem, rituais e sistema de crenças.

${ }^{3}$ Entre as publicações que relatam estudos correlacionais de larga escala ou que apresentam revisões de tais estudos, pode-se destacar as seguintes: Cleman e outros (1966), Jencks e outros (1972), Davie, Butler e Goldstein (1972), Brandão e outros (1983), Tomlison (1983), Bianchi (1984), Grantham-Mcgregor (1987), Mortimore e outros (198), Gottfried, Gotffried e Bathurst (1988), Lerner e Galambos (1988), Hasenbalg e Silva (1990), Pollit (1990), llon e Mook (1991), Psacharoupoulos e Yang (1991), Dauber, Alexander e Entwisle (1993), Schneider e Coleman (1993), Wolff, Schiefelbein e Valenzuela (1994), Evans (1995), Beyer (1995), Patrinos e Psacharopoulos (1996) e OFSTED (Office for Standards in Education) (1996).
} 
VAUGHAN, 1988) - que constituiu a primeira etapa deste trabalho - teve, como um de seus objetivos iniciais, verificar a repetibilidade dos achados desses estudos em relação à população pelotense, já que se dispunha de um amplo banco de dados de base populacional.

Das aproximadamente 6.000 crianças que constituem a coorte original do estudo, $3.903^{4}$ foram localizadas nas 98 escolas de Ensino Fundamental da zona urbana da cidade. Às variáveis de cada criança, já acumuladas nesse banco de dados, foi acrescentada a seguinte informação: ocorrência de pelo menos um episódio de repetência ou evasão durante o tempo de escolarização, até a data da coleta dos dados (ano de 1991, quando as crianças estavam completando nove anos de idade). Essa informação constituiu a variável dependente do estudo e foi denominada "fracasso escolar".

As 14 variáveis independentes (explanatórias) incluídas no estudo de correlação eram relativas a aspectos pessoais e familiares dos estudantes e foram selecionadas com base em revisão de literatura sobre o assunto e em sua plausibilidade, isto é, na possibilidade de que pudessem estar associadas ao seu desempenho escolar. Como o fracasso é entendido como um fenômeno que apresenta uma estrutura de determinação hierarquizada, essas variáveis independentes foram distribuídas em distintos níveis (Figura 1) e suas associações com o fracasso escolar foram analisadas através de um modelo de regressão logística hierárquica. Tal modelo não permite que o efeito de variáveis distais (aquelas cujo efeito se exerce associado a outras) seja absorvido pelo efeito de variáveis proximais (aquelas cujo efeito se exerce diretamente) que representam, em realidade, os mecanismos através dos quais as variáveis distais exercem seus efeitos ${ }^{5}$. A magnitude das associações entre as variáveis independentes e a variável dependente (fracasso) foi calculada através de odds ratios ${ }^{6}$ e a significância estatística através do teste de razão de probabilidades ${ }^{7}$. Para as variáveis ordinais, foram realizados testes para tendência linear.

As variáveis foram adicionadas à análise de acordo com o nível que ocupavam no modelo apresentado na Figura 1. Aquelas localizadas no Nível 1, por exemplo, foram incluídas no passo 1 da análise e assim por diante. $\bigcirc$ modelo utilizado não tinha a intenção de esgotar os determinantes do fracasso escolar. Tal modelo foi considerado como a forma mais adequada de organizar as variáveis disponíveis para a análise, baseando-se em informações obtidas em outras pesquisas e em fases anteriores do Estudo Longitudinal de Pelotas.

\footnotetext{
${ }^{4}$ Excluindo as que morreram (4\% da coorte), supõe-se que as não-encontradas mudaram-se da cidade, estudam em escolas rurais ou em escolas localizadas em áreas que integravam a cidade de Pelotas em 1982 e já se haviam tornado independentes em 1991. Entre as 4.094 crianças que foram localizadas nas escolas, 173 estavam com as informações incompletas a respeito de seu desempenho escolar. As 18 que freqüentavam escolas especiais foram excluídas das análises.

${ }^{5} \mathrm{O}$ modelo não permite, por exemplo, que o efeito das variáveis socioeconômicas (distais), seja absorvido pelo efeito de variáveis nutricionais (proximais), já que o efeito das primeiras sobre o fracasso escolar é exercido tanto diretamente quanto através do efeito das segundas (a desnutrição também está associada a fatores sócio-econômicos).

${ }^{6}$ Odds ratio é uma medida de efeito; é o número pelo qual se multiplica a chance de fracasso para cada unidade da variável independente. (MENARD, 1995; KIRKWOOD, 1988). Para variáveis categóricas, escolhe-se uma categoria como base (odds ratio $=1.00$ ) e calcula-se os outros odds ratios em relação a ela.

${ }^{7}$ Esse teste permite comparar valores observados com valores preditos de uma variável dependente (HOSMER; LEMESHOW, 1989).
} 
Figura 1: Modelo explanatório do fracasso escolar que guiou a análise de regressão logística hierárquica

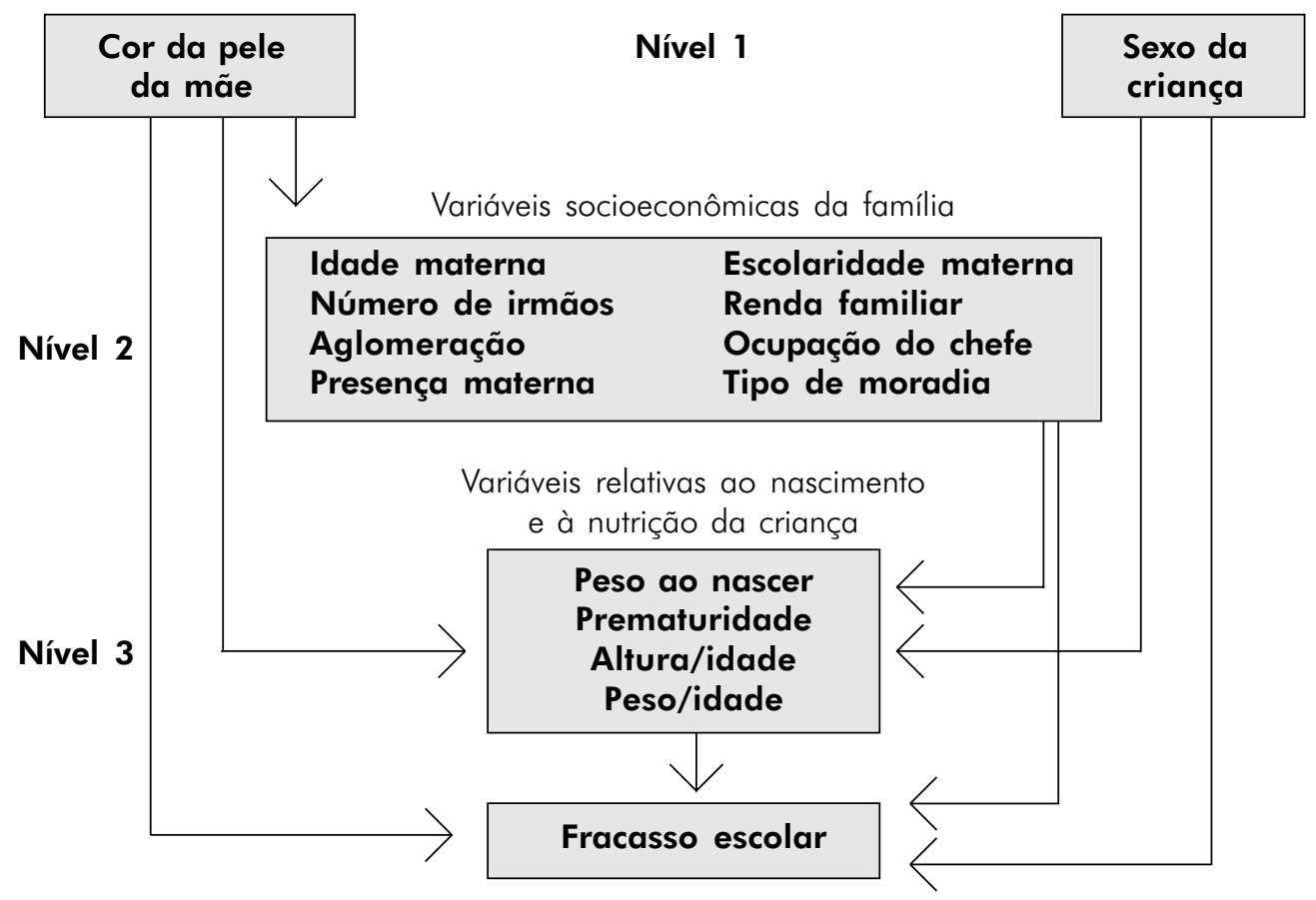

A análise dos dados, obtidos através do quarto acompanhamento da coorte, mostrou que a maioria das crianças localizadas nas escolas (50\%) freqüentava a terceira série, enquanto que $31 \%$ freqüentavam a segunda série, $14 \%$, a primeira e $5 \%$ a quarta ou a quinta série do Ensino Fundamental. $O$ percentual de crianças que já havia repetido série ou se evadido da escola (pelo menos uma vez durante sua vida acadêmica - fracasso), era de $27 \%$.

A Tabela 1 ilustra as associações en- tre as variáveis explanatórias selecionadas e o fracasso escolar. Os odds ratios brutos (com seus intervalos de confiança de $95 \%$ ) indicam o risco de fracasso para cada uma das variáveis explanatórias, tomadas separadamente. Os odds ratios ajustados indicam o risco de fracasso no modelo multivariado, em que o efeito de cada variável foi ajustado em relação ao efeito das outras variáveis presentes naquela etapa da análise. Os níveis de significância mostram os resultados dos testes de razão de probabilidades. 
Tabela 1: Fatores de risco para fracasso escolar obtidos através de regressão logística hierárquica (Pelotas, 1991).

\begin{tabular}{|c|c|c|c|c|c|c|}
\hline Variáveis & $\begin{array}{c}\text { Total } \\
\text { (crianças) } \\
\mathbf{n} \\
(\%)\end{array}$ & $\begin{array}{c}\text { Fracasso } \\
\text { (crianças) } \\
n \\
(\%)\end{array}$ & $\begin{array}{c}\text { Odds ratios } \\
\text { (brutos) } \\
\text { (95\% } \\
\text { C.I.) }\end{array}$ & $\begin{array}{l}\mathbf{P} \\
*\end{array}$ & $\begin{array}{c}\text { Odds ratios } \\
\text { (ajustados) } \\
\text { (95\% } \\
\text { I.C.) }\end{array}$ & $\begin{array}{l}\mathbf{P} \\
*\end{array}$ \\
\hline $\begin{array}{l}\text { Cor } \\
\text { (pele } \\
\text { materna) }\end{array}$ & & & & $<0.001$ & & $<0.001$ \\
\hline Branca & $\begin{array}{l}3328 \\
(82.2)\end{array}$ & $\begin{array}{c}779 \\
(24.1)\end{array}$ & 1.00 & & $1.00 \#$ & \\
\hline Outra & $\begin{array}{l}698 \\
(17.8)\end{array}$ & $\begin{array}{l}315 \\
(45.1)\end{array}$ & $\begin{array}{c}2.60 \\
(2.19-3.08)\end{array}$ & & $\begin{array}{c}2.59 \# \\
(2.19-3.08)\end{array}$ & \\
\hline $\begin{array}{l}\text { Sexo da } \\
\text { criança }\end{array}$ & & & & $<0.001$ & & $<0.001$ \\
\hline Feminino & $\begin{array}{c}1914 \\
(48.7)\end{array}$ & $\begin{array}{c}481 \\
(25.1)\end{array}$ & 1.00 & & $1.00 \#$ & \\
\hline Masculino & $\begin{array}{l}2015 \\
(51.3)\end{array}$ & $\begin{array}{l}1433 \\
(30.5)\end{array}$ & $\begin{array}{c}1.30 \\
(1.13-1.50)\end{array}$ & & $\begin{array}{c}1.29 \# \\
(1.12-1.49)\end{array}$ & \\
\hline $\begin{array}{l}\text { Idade } \\
\text { materna }\end{array}$ & & & & $<0.01$ & & $<0.01$ \\
\hline$<21$ & $\begin{array}{l}771 \\
(19.6)\end{array}$ & $\begin{array}{c}253 \\
(32.8)\end{array}$ & $\begin{array}{c}1.35 \\
(1.12-1.62)\end{array}$ & & $\begin{array}{c}1.22 @ \\
(0.99-1.50)\end{array}$ & \\
\hline $21-35$ & $\begin{array}{l}2818 \\
(71.7)\end{array}$ & $\begin{array}{l}745 \\
(26.4)\end{array}$ & 1.00 & & 1.00@ & \\
\hline$>35$ & $\begin{array}{l}340 \\
(8.7)\end{array}$ & $\begin{array}{c}97 \\
(28.5)\end{array}$ & $\begin{array}{c}1.10 \\
(0.85-1.43)\end{array}$ & & $\begin{array}{c}0.81 @ \\
(0.60-1.08)\end{array}$ & \\
\hline \multicolumn{6}{|l|}{ Número } & \\
\hline Nenhum & $\begin{array}{l}1058 \\
(28.9)\end{array}$ & $\begin{array}{c}229 \\
(21.6)\end{array}$ & 1.00 & & 1.00@ & \\
\hline 1 ou 2 & $\begin{array}{l}1292 \\
(35.3)\end{array}$ & $\begin{array}{c}308 \\
(23.8)\end{array}$ & $\begin{array}{c}1.13 \\
(0.93-1.37)\end{array}$ & & $\begin{array}{c}1.21 @ \\
(0.97-1.49)\end{array}$ & \\
\hline 3 & $\begin{array}{l}1011 \\
(27.6)\end{array}$ & $\begin{array}{c}323 \\
(31.9)\end{array}$ & $\begin{array}{c}1.71 \\
(1.40-2.09)\end{array}$ & & $\begin{array}{c}1.66 @ \\
(1.33-2.08)\end{array}$ & \\
\hline 4 ou mais & $\begin{array}{l}298 \\
(8.1)\end{array}$ & $\begin{array}{c}149 \\
(50.0)\end{array}$ & $\begin{array}{c}3.65 \\
(2.78-4.79)\end{array}$ & & $\begin{array}{c}2.36 @ \\
(1.73-3.23)\end{array}$ & \\
\hline Aglomeração & & & & $<0.05$ & & $0.7518+$ \\
\hline$<4$ pessoas & $\begin{array}{l}2348 \\
(71.7)\end{array}$ & $\begin{array}{c}628 \\
(26.7)\end{array}$ & 1.00 & & 1.00@ & \\
\hline 4 pessoas ou mais & $\begin{array}{l}927 \\
(28.3)\end{array}$ & $\begin{array}{c}285 \\
(30.7)\end{array}$ & $\begin{array}{c}1.24 \\
(1.04-1.48)\end{array}$ & & $\begin{array}{c}1.02 @ \\
(0.84-1.23)\end{array}$ & \\
\hline $\begin{array}{l}\text { Escolaridade } \\
\text { mãe }\end{array}$ & & & $<0.0001 \&$ & & $<0.001 \&$ & \\
\hline 0 até $2 a$. série & $\begin{array}{c}445 \\
(11.3)\end{array}$ & $\begin{array}{c}239 \\
(53.7)\end{array}$ & $\begin{array}{c}2.32 \\
(2.01-2.67)\end{array}$ & & $\begin{array}{c}2.34 @ \\
(1.79-3.06)\end{array}$ & \\
\hline 3a. até 5 a. série & $\begin{array}{l}1501 \\
(38.2)\end{array}$ & $\begin{array}{c}529 \\
(35.2)\end{array}$ & $\begin{array}{c}1.10 \\
(0.99-1.22)\end{array}$ & & $\begin{array}{c}1.49 @ \\
(1.24-1.80)\end{array}$ & \\
\hline 6a. série ou mais & $\begin{array}{c}1979 \\
(50.4)\end{array}$ & $\begin{array}{c}325 \\
(16.4)\end{array}$ & 1.00 & & 1.00@ & \\
\hline
\end{tabular}


Tabela 1: Fatores de risco para fracasso escolar obtidos através de regressão logística hierárquica (Pelotas, 1991) (continuação).

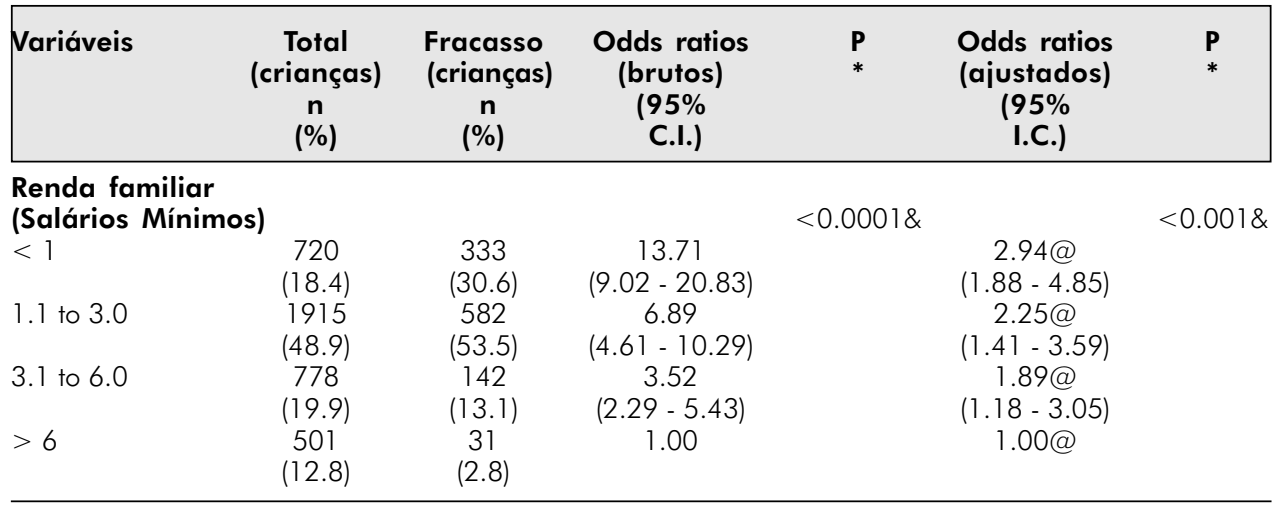

\section{Ocupação}

do chefe

propriet./administr/

profissionais

não manual

217

(5.9)

8

583

(3.7)

65

$<0.0001$

$<0.001$

1.00

1.00@

3.21

1.77@

(16.0)

manual qualificado

170

(4.7)

manual semiqualif. 1683

(46.1)

manual não qualif.

fora da população

997

(27.3)

econom. ativa

\section{Tipo de moradia}

apartamento

554

(15.2)

tijolo

mista

1853
$(50.8)$

246

(6.7)

madeira irregular

tijolo irregular

"maloca"

\section{1}

(15.4)

113

(3.1)

319

(8.7)

Peso do nascer

$<2,000 \mathrm{~g}$

$2,000 \mathrm{~g}$ to $2,499 \mathrm{~g}$

$2,500 \mathrm{~g}$ to $3,499 \mathrm{~g}$

$>3,500 \mathrm{~g}$
64

(1.6)

209

(5.3)

2436

(62.0)

1220

(31.1)
(11.1)

29

(17.1)

487

(28.9)

422

(42.3)

(1.52- 6.80)

5.15

$(42.3)$

113

(13.7)

399

(21.5)

76

(30.7)

219

(39.0)

48

(42.5)

186

(58.3)

$(2.29-11.61)$

10.41

$(5.11-21.22)$

18.77

$(9.18-38.37)$

$<0.0001$

1.00

1.73

(1.32 - 2.26)

2.90

(2.01-4.18)

4.11

(3.05 - 5.54)

4.73

(3.03 - 7.40)

9.03

$(6.48-12.59)$

$<0.001 \&$

2.35

(1.34 - 4.14)

1.55

(0.81-3.91)

2.47@

(1.05-5.85)

3.07@

(1.41-6.72)

3.56@

(1.61-7.89)

1.00@

1.22@

(0.92 - 1.62)

1.33@

(0.90-1.96)

1.74@

(1.26-2.41)

$1.83 @$

(1.14-2.94)

2.61@

$(1.80-3.78)$

$1.40 \$$

$(0.73-2.70)$

$1.12 \$$

(1.12 - 2.16)

1.12

$(0.76-1.64)$

$0.95 \$$

$(0.95-1.32)$

1.00

(28.2)

$(9.18-38.37)$

(25.3) 
Tabela 1: Fatores de risco para fracasso escolar obtidos através de regressão logística hierárquica (Pelotas, 1991) (continuação).

\begin{tabular}{|c|c|c|c|c|c|c|}
\hline Variáveis & $\begin{array}{c}\text { Total } \\
\text { (crianças) } \\
\mathbf{n} \\
(\%)\end{array}$ & $\begin{array}{c}\text { Fracasso } \\
\text { (crianças) } \\
n \\
(\%)\end{array}$ & $\begin{array}{l}\text { Odds ratios } \\
\text { (brutos) } \\
\text { (95\% } \\
\text { C.I.) }\end{array}$ & $\begin{array}{l}\mathbf{P} \\
*\end{array}$ & $\begin{array}{c}\text { Odds ratios } \\
\text { (ajustados) } \\
\text { (95\% } \\
\text { I.C.) }\end{array}$ & $\begin{array}{l}\mathbf{P} \\
*\end{array}$ \\
\hline $\begin{array}{l}\text { Prematuridade } \\
\text { Sim } \\
\text { Não }\end{array}$ & $\begin{array}{l}166 \\
(5.2) \\
3002 \\
(94.8)\end{array}$ & $\begin{array}{c}51 \\
(30.7) \\
756 \\
(25.2)\end{array}$ & $\begin{array}{c}1.34 \\
(0.94-1.92) \\
1.00\end{array}$ & 0.1129 & $\begin{array}{c}0.85 \$ \\
(0.56-1.31) \\
1.00\end{array}$ & $0.43858+$ \\
\hline $\begin{array}{l}\text { Peso/idade } \\
\text { (Desvios-padrão) } \\
<-2 \\
-2 \text { to }-1.01 \\
-1 \text { to } 1 \\
>1.01\end{array}$ & $\begin{array}{c}108 \\
(2.9) \\
613 \\
(16.7) \\
2412 \\
(65.9) \\
529 \\
(14.4)\end{array}$ & $\begin{array}{c}56 \\
(51.9) \\
228 \\
(37.2) \\
655 \\
(27.2) \\
75 \\
(14.2)\end{array}$ & $\begin{array}{c}6.33 \\
(4.01-10.00) \\
3.54 \\
(2.64-4.76) \\
2.17 \\
(1.67-2.82) \\
1.00\end{array}$ & $<0.0001 \&$ & $\begin{array}{c}1.33 \$ \\
(0.74-2.41) \\
1.23 \$ \\
(2.64-4.76) \\
1.32 \$ \\
(0.97-1.80)\end{array}$ & $0.0858 \&$ \\
\hline $\begin{array}{l}\text { Altura/idade } \\
\text { (Desvios-padrão) } \\
<-2 \\
-2 \text { to }-1.01 \\
-1 \text { to } 1 \\
>1.01\end{array}$ & $\begin{array}{c}272 \\
(7.4) \\
743 \\
(20.3) \\
2291 \\
(62.5) \\
357 \\
(9.7)\end{array}$ & $\begin{array}{c}143 \\
(52.6) \\
284 \\
(38.2) \\
537 \\
(23.4) \\
51 \\
(14.3)\end{array}$ & $\begin{array}{c}6.56 \\
(4.47-9.63) \\
3.69 \\
(2.64-5.15) \\
1.82 \\
(1.33-2.49) \\
1.00\end{array}$ & $<0.0001 \&$ & $\begin{array}{c}1.96 \$ \\
(1.17-3.26) \\
1.58 \$ \\
(1.05-2.38) \\
1.14 \$ \\
(0.78-1.64) \\
1.00 \$\end{array}$ & $<0.001 \&$ \\
\hline
\end{tabular}

* Teste de razão de probabilidades

\& Teste para tendência linear em proporções (unicaudal)

\# Modelo 1: Cor da pele materna, sexo da criança

@ Modelo 2: Modelo1 + Idade materna, Número de irmãos, Aglomeração na moradia, Escolaridade materna, Renda familiar mensal, Ocupação do chefe da família e Tipo de moradia

$+\mathrm{n}=3045$

Tabela 1: Fatores de risco para fracasso escolar obtidos através de regressão logística hierárquica (Pelotas, 1991)(cont.). 
Os dados da Tabela 1 indicam que somente 10 das 14 variáveis utilizadas na análise representaram contribuições significativas ao modelo multivariado. Os achados do Estudo Longitudinal de Pelotas foram semelhantes aos de um conjunto de pesquisas correlacionais nacionais e estrangeiras revisadas (listadas na nota de rodapé 3). Tais pesquisas não apresentam unanimidade, em relação ao grau de influência exercido por cada uma das variáveis, pois têm características singulares: investigaram sujeitos de idades diferentes e grupos de variáveis distintas, definidas e medidas também de formas diferentes. Entretanto, indicam que variáveis relacionadas ao status socioeconômico das famílias são fortemente associadas ao fracasso escolar dos estudantes que a elas pertenciam.

Resumindo os achados do estudo de Pelotas (Tabela 1), podemos salientar que os maiores riscos de fracasso escolar foram encontrados entre os filhos de mães não brancas $(2,6$ vezes maior do que o risco dos filhos de mães brancas); filhos de mães analfabetas ou com até dois anos de escolaridade (2,3 vezes maior do que o risco dos filhos de mães com seis ou mais anos de escolaridade); filhos de famílias com renda mensal menor do que um salário mínimo $(2,9$ vezes maior do que o risco de filhos de famílias com renda superior a seis salários mínimos); filhos de famílias cujo chefe era um trabaIhador manual não qualificado ou estava fora da população economicamente ativa (3,6 vezes maior do que o risco de filhos de proprietários, administradores ou profissionais liberais); estudantes que moravam em "malocas" (2,6 vezes maior do que o risco dos que moravam em apartamentos); e estudantes que tinham quatro ou mais irmãos $(2,4$ vezes maior do que o risco de filhos únicos). Os meninos e os estudantes desnutridos também apresentaram maiores riscos de fracassar na escola.

Embora, como foi referido anteriormente, se considere importante identificar os grupos de crianças em risco de fracasso escolar e estimar o grau de influência de cada fator de risco, é essencial que se levem em conta as complexas relações entre fracasso e desempenho escolar, que não se limita ao efeito das variáveis estudadas - o modelo de análise utilizado conseguiu explicar apenas $29 \%$ da variância no desempenho escolar dos estudantes. Além disso, ao se examinarem esses resultados, não se pode esquecer que os critérios de avaliação não são uniformes entre as escolas e que, portanto, um estudante que foi reprovado em uma instituição poderia ter sido aprovado em outra.

As investigações que incluem apenas aspectos pessoais e familiares dos estudantes tornam-se limitadas ao deixar de considerar a influência dos fatores intraescolares sobre o desempenho desses estudantes. A exclusão destes fatores pode levar a um processo de culpabilização das próprias crianças, e de suas famílias, pelo fracasso, à crença de que o processo de escolarização é semelhante em todas as escolas e de que o papel destas não é importante na determinação do rendimento de seus estudantes.

Os estudos de correlação não conseguem explicar os processos que levam ao fracasso escolar crianças portadoras dos fatores de risco. Eles também não indicam como a influência desses fatores pode ser modificada pelas características específicas de cada instituição escolar. Foi com a in- 
tenção de contribuir para o entendimento de tais aspectos que se organizou uma investigação de caráter qualitativo, na segunda etapa desta pesquisa. Os achados dos estudos de casos das duas escolas serão expostos a seguir. Antes, porém, será apresentado um resumo do referencial teórico que orientou a realização desses estudos: as idéias de Vygotsky (1978), Leontiev (1981) e Bakhtin (VOLOSINOV, 1973 ), sobre a formação social da mente e a relação entre cognição e contexto, integradas ao modelo de transmissão cultural de Bernstein.

\section{Cognição e contexto: o fracasso escolar e os fatores intra-escolares}

Vygotsky (1978) acreditava que a mente humana era formada através de transações dialéticas entre o indivíduo e o meio social. Bakhtin/Volosinov ${ }^{8}$ afirmava que a consciência individual era conseqüência da inserção das pessoas no mundo dos signos criados por grupos organizados (VOLOSINOV, 1973). Leontiev (1981, 1986), por seu lado, argumentava que a forma com que os sistemas de atividade? são organizados, no nível da sociedade, influencia na maneira pela qual um indivíduo ou grupo desenvolve e domina um tipo de ação orientada para um objetivo (WERTSCH; MINICK; ARNS, 1984).

Embora afirmando o papel do ambiente sociocultural no desenvolvimento mental, Vygotsky, Bakhtin e Leontiev não exploraram as maneiras específicas através das quais as instituições sociais exercem sua influência sobre os indivíduos. Tal tarefa foi cumprida por Bernstein (1977, 1981, 1990, 1996), que desenvolveu um modelo geral para explicar este processo dentro das instituições educacionais. Para Bernstein (1996), as escolas não podem ser consideradas como instituições neutras, que cumprem apenas o papel de ensinar conteúdos e habilidades aos novos membros de uma sociedade. As escolas são transmissoras de mensagens ideológicas e traduzem as relações de poder da sociedade em um discurso pedagógico que regula as formas da consciência e da identidade de seus estudantes. Ao posicionar os estudantes de diferentes grupos (sociais, regionais, de gênero, de etnia, de religião) em diferentes níveis educacionais, por exemplo, as escolas preservam as relações estruturais que existem nas sociedades.

Bernstein (1996) descreve o discurso pedagógico como um "aninhamento" (embedding) de dois outros discursos: o das habilidades e suas inter-relações (discurso instrucional) e o da ordem, das relações e da identidade social (discurso regulativo). Estes dois discursos são geralmente considerados como distintos e mantidos separados, como se houvesse uma conspiração para esconder esse "aninhamento" em que o discurso regulativo é o que geralmente predomina e produz ordem no discurso instrucional.

\footnotetext{
${ }^{8}$ Existe, na literatura, uma disputa sobre a autoria dos textos de Volosinov. Alguns autores afirmam que Bakhtin escrevia sob esse pseudônimo por razões de perseguição política. Outros argumentam que Volosinov realmente existiv e trabalhava com Bakhtin (WERTSCH, 1991; BAKHURST, 1996; EMERSON, 1996).

${ }^{9}$ Baseado em Leontiev (1981), Russel (1997) definiu um sistema de atividade como qualquer tipo de interação humana continuada, dirigida a objetos, historicamente condicionada, dialeticamente estruturada e mediada por instrumentos: uma família, uma organização religiosa, um grupo de advocacia, um movimento político, um curso, uma escola, uma disciplina, um laboratório de pesquisa, uma profissão e assim por diante.
} 
Embora uma análise mais aprofundada permita que se perceba esse papel socializador da escola, seu discurso tenta desvincular a hierarquia de sucesso, existente em seu interior, das hierarquias externas ao sistema educacional.

As posições teóricas acima contrastam com a perspectiva individualista que explica as variações no comportamento humano em termos de diferenças cognitivas, afetivas e valorativas e que, conseqüentemente, atribui as variações no desempenho acadêmico dos estudantes a essas mesmas diferenças. $\bigcirc$ enfoque correlacional do fracasso escolar, com sua ênfase em fatores extra-escolares, presta-se para reforçar esta perspectiva individualista que o estudo qualitativo, realizado na segunda etapa deste trabalho, tentou desmistificar.

\section{Os estudos de caso}

As escolas selecionadas para os estudos de caso estavam localizadas em um mesmo bairro da periferia da cidade de Pelotas e eram administradas pelo mesmo órgão público. Estas escolas eram freqüentadas por crianças da classe trabalhadora - o grupo mais afetado pelo fracasso escolar - e foram escolhidas por apresentarem semelhanças em termos da prevalência dos fatores de risco identificados no estudo de correlação. Seus estudantes pertenciam aos mesmos grupos de renda familiar, tipo de ocupação do chefe da família, tamanho de família e tipo de moradia. As escolas diferiam em termos das taxas de fracasso escolar entre seus estudantes: $43 \%$ dos que freqüentavam as primeiras cinco séries do Ensino Fundamental na escola com alto índice de fracasso (AF) já haviam repetido uma série ou evadido da escola (pelo menos uma vez), até o ano de 1995. Na es- cola com baixo índice de fracasso (BF), 10\% dos estudantes apresentavam esse tipo de desempenho escolar.

A investigação dos processos intra-escolares associados ao fracasso ocorreu através de entrevistas - com 10 professoras (de primeira a quarta série) de cada escola, direção e famílias dos estudantes - e através de observações - realizadas nas salas de aula de todos as professores de primeira à quarta série e durante todas as outras atividades escolares. Foram também utilizadas redações de crianças de duas turmas de quarta série (uma de cada escola) que descreviam suas escolas. Dados sócio-econômicos dos estudantes e dos professores foram colhidos nos arquivos das instituições. $O$ trabalho de campo teve a duração de dois meses.

\section{Achados dos estudos de caso}

Os dados obtidos através dos estudos de caso são complexos e não poderão ser apresentados em sua íntegra neste trabalho. As diferenças mais significativas entre as duas escolas serão comentadas a seguir. Juntamente com tais diferenças, serão apresentados os resultados de outros estudos que abordaram os processos intra-escolares relacionados com o fracasso escolar e que confirmam os achados da investigação realizada em Pelotas.

\section{Estrutura física}

Embora teoricamente enfrentando a mesma escassez de recursos financeiros, já que eram administradas pelo mesmo órgão público, as escolas tinham aparências distintas. AF apresentava-se em estado precário de conservação: paredes externas e internas su- 
jas e mofadas, falta de vidros nas janelas, fechaduras quebradas, buracos no piso das salas e quadros de giz com áreas impróprias para a escrita. BF, por sua vez, tinha um aspecto mais limpo e bem cuidado, sugerindo um maior grau de investimento nesta escola, por parte de suas professoras e funcionárias, e confirmando os achados de Sammons e outros (1995) que indicam a existência de uma relação entre rendimento escolar dos estudantes e características físicas da escola. $O$ interesse em relação às instalações escolares em BF foi confirmado através do conteúdo das respostas dadas pelas professoras e pela direção à pergunta de como a sua escola poderia melhorar nesta área. Enquanto as professoras de AF apenas mencionaram a necessidade de consertos, as professoras de BF expressaram o desejo de expansão: construção de mais salas de aula, salas para vídeo, biblioteca e área para Educação Física, demonstrando um desejo de que a escola crescesse e progredisse.

\section{Cultura escolar}

A partir do referencial de Bernstein, pode-se descrever a cultura da escola $\mathrm{AF}$ como apresentando um caráter regulativo, isto é, valorizando os aspectos de ordem social: a missão básica da escola parecia ser assistencial. A predominância regulativa era tão marcante que o discurso instrucional desta escola - aquele que é, em geral, mais saliente - permanecia relativamente sufocado. A grande importância dos aspectos regulativos foi sumarizada com precisão por um ex-estudante dessa escola (um dos integrantes do Estudo Longitudinal de 1982) que fez o seguinte comentário: "Parece que a gente está em casa lá naquele colégio".
A impressão do rapaz era compartilhada pela pesquisadora, por algumas das professoras que trabalhavam na escola e por estagiárias do Curso de Pedagogia da Universidade Federal de Pelotas, que lá desenvolviam suas atividades, à época do trabalho de campo. Dados obtidos através de diferentes fontes indicavam a existência, em $A F$, de uma atmosfera "aconchegante" em que predominava a preocupação com o bem-estar pessoal e com as relações interpessoais - a ponto de sentir-se que os assuntos acadêmicos eram secundários.

As descrições da escola produzidas pela turma de estudantes de quarta série também espelhavam a clara ênfase do discurso regulativo em AF. Essas descrições não mencionavam nenhum aspecto instrucional da escola (ensino, aprendizagem ou benefícios da escolarização), como aconteceu nas redações dos estudantes de uma turma equivalente na escola BF. As descrições, em AF, versavam apenas sobre tópicos ligados aos relacionamentos entre estudantes e entre estudantes, professores e funcionárias (aspectos regulativos), como ilustram os extratos que se seguem ${ }^{10}$, que caracterizam a percepção predominante em cada instituição:

- Hoje na minha escola todos estão sem dinheiro a diretora da minha escola está triste porque ela precisa de dinheiro para arrumar o rádio e comprar grade para botar nas janelas.

- A minha escola é a [nome da escola e a rua onde está localizada]. na escola eu me sinto bem causa que eu tenho muitos amigos.

(Estudante de uma turma da $4^{a}$. série, escola AF).

${ }^{10}$ Os textos foram reproduzidos de maneira fiel e, portanto, apresentam alguns erros de linguagem. 
- Minha escola é grande bonita. tem 13 salas, tem pré até a oitava as professora da escola são muito boa principalmente a [nome da professora].

- O nome da minha escola é [nome da escola].

- A minha escola tem refeitório, tem Barzinho você sabe que o lanche do refeitório e do Barzinho é muito Bom.

- A minha escola esta vendendo abricó para os alunos e também professores com o nome da escola.

- Também minha escola ensina muitos bem as Matérias e na sala que eu estudo eu tenho 28 colegas que são muito meus amigos.[...].

(Estudante de uma turma da $4^{a}$. série, escola BF, grifo nosso).

Os relacionamentos entre professores, direção e funcionárias, as histórias de vida dos estudantes, a preocupação em manter as crianças dentro da escola (em oposição a permitir que permanecessem nas ruas), o cuidado assistencial, a preocupação com o fornecimento de "modelos de conduta" às crianças, foram temas salientes no discurso das professoras de AF. A ênfase dos aspectos regulativos também estava presente no discurso das professoras de BF, embora com menos intensidade.

As professoras de BF também avaliaram mais positivamente sua escola do que as de AF. Ao citar aspectos positivos que caracterizavam suas escolas, a maioria das professoras de BF referiu-se a características instrucionais - tais como a boa qualidade dos profissionais e as vantagens que a escola oferecia aos estudantes - refletindo os resultados de Rosenholtz (1991), em sua descrição de algumas escolas norteamericanas que classificou como "ricas em aprendizagem". Em tais escolas, onde a maioria dos estudantes apresentava bom rendimento, eram comuns as discussões de assuntos acadêmicos e a valorização dos mesmos. Em AF, as professoras citaram principalmente aspectos regulativos: o bom relacionamento entre elas e o esforço para ajudar os estudantes. As redações dos estudantes de quarta série, anteriormente citadas, também revelaram que a maioria dos que freqüentavam BF não apresentava nenhuma crítica a sua escola. Em AF isto aconteceu com a minoria.

Ao descrever seu modelo de "bom professor", a maior parte das professoras de AF novamente mencionou qualidades ligadas à capacidade dos professores de serem amigos dos estudantes, dar-lhes apoio emocional e servir-lhes de modelos de conduta. Esse fato revelou, mais uma vez, a tendência a valorizar aspectos regulativos. Em BF, por outro lado, a maioria das professoras, além de citar estas características regulativas, mencionou também características instrucionais, como habilidades acadêmicas e técnicas.

As observações em sala de aula revelaram muitas semelhanças e algumas diferenças nas práticas pedagógicas das duas escolas. A predominância, em AF, de uma atividade que as professoras denominavam "exercícios de fixação", foi uma das diferenças encontradas. Os estudantes despendiam muito tempo copiando do quadro e resolvendo exercícios repetitivos nesta escola. Em $B F$, esta prática era desenvolvida em menor escala e observou-se um maior número de ocasiões em que novos conteúdos eram introduzidos, indicando que os professores acreditavam na possibilidade e na necessidade dos estudantes de aprender coisas novas. 
comportamento dos professores de AF estava de acordo com os dados colhidos por Waxman e Padron (1995), que estudaram as características das escolas norte-americanas freqüentadas por estudantes de baixo rendimento acadêmico: tais escolas devotavam menos tempo ao desenvolvimento de habilidades mentais superiores, enfatizando a repetição de conteúdos já estudados.

Em adição à menor ênfase colocada no ensino de conteúdos novos, um maior número de professoras da escola AF relatou que introduzia tais conteúdos escrevendoos no quadro de giz para que fossem copiados pelos estudantes. Isto sugere uma concepção de ensino como simples transmissão de informações. Em BF, um grande número de professoras relatou que, antes de introduzir um novo conteúdo, investigava $\circ$ que as crianças sabiam sobre $O$ assunto e tentava integrá-lo a aspectos da vida diária das mesmas.

Para ilustrar mais claramente o descaso com os aspectos instrucionais do discurso pedagógico em $A F$, é interessante reproduzir as palavras de uma de suas professoras, ao referir-se à sua "filosofia de ensino" relativa às crianças de classe trabalhadora:

Eles só precisam aprender o essencial: cálculos, escrever, ler e caligrafia. É bobagem ensinar pra eles História, Geografia e Ciências, então eu ensino um pouquinho, assim, só "pra" constar.

Embora esta tendência a despender menor tempo na disciplina de Estudos Sociais tenha sido apontada por Penin (1994) como uma característica das escolas de Ensino Fundamental brasileiras, os dados sugerem que, em $A F$, essa tendência aparecia de forma contundente.
A desvalorização dos aspectos instrucionais da escolarização, em AF, ficou, mais uma vez, evidente através do grau de improvisação constatado no ensino de Artes nesta escola. A professora que trabalhava na área, durante as observações de suas aulas, desculpava-se pela falta de organização alegando não ter tido treinamento para trabalhar com a disciplina e justificando as atividades improvisadas que desenvolvia com a necessidade de "encher o tempo de algum jeito". A professora explicou que se tinha voluntariado para o cargo "pra ajudar", já que "não tinha ninguém na escola para assumir a disciplina". $\bigcirc$ fato de que as aulas eram interrompidas a qualquer momento (mesmo durante as provas) para que as crianças fossem merendar, também reforçava a percepção de que os aspectos instrucionais eram colocados em segundo plano, em AF: os horários de refeição de cada turma eram aleatórios e organizados pelas merendeiras. Em BF, embora os horários também não fossem fixos, quando as atividades desenvolvidas em aula eram importantes, ocorriam alterações nos mesmos para evitar interrupções, revelando um maior grau de priorização das atividades de ensino.

Os dados relativos às práticas avaliativas das duas escolas mostraram que os estudantes eram avaliados com maior seriedade, maior formalidade e uma gama maior de critérios em BF do que em AF. Este fato anulou a possibilidade de que a diferença nas taxas de fracasso escolar entre as duas escolas fosse fruto de procedimentos mais rigorosos na escola onde o desempenho dos estudantes era pior (AF). Nesta escola observou-se um maior número de avaliações, assim como um caráter mais informal e uma menor abrangência de conteúdos nas mes- 
mas. Nas palavras de algumas professoras de $A F$, havia necessidade desse procedimento para que os estudantes tivessem "mais chances de passar".

A maioria das professoras das duas escolas considerava que o fracasso é causado por fatores extra-escolares - relacionados principalmente às características familiares dos estudantes. Este tipo de entendimento reflete uma forte tendência, observada entre as professoras do Ensino Fundamental em diversas investigações realizadas no Brasil (MELLO, 1985; VERHINE; MELO, 1988; DAVICO, 1990; GAMA et al., 1991 ; PENIN, 1994; ARROYO, 1997). No entanto, quando o conteúdo das respostas foi analisado em relação a um continuum regulativo/instrucional, as opiniões das professoras da escola BF localizaram-se mais próximas do extremo instrucional desse continuum do que as opiniões das professoras de AF. As professoras de BF enfatizavam a falta de suporte acadêmico dado aos estudantes por suas famílias e, um número pequeno delas, mencionava o desempenho pobre dos professores ou a inadequação do sistema escolar para atender às necessidades de crianças da classe trabalhadora, como causas do fracasso, como mostra o depoimento a seguir:

- Olha, eu vou te dizer isto bem baixinho para que ninguém me ouça. Eu penso que uma das causas do fracasso escolar é a falta de interesse por parte do professor. Eu acho que esta é uma das causas, porque o professor que está realmente interessado, ele faz! Ele faz alguma coisa, ele descobre um jeito, ele procura formas diferentes de ensinar e [...] faz alguma coisa! Eu diria que esta é uma das causas principais.
Em AF, a causa priorizada era a falta de estabilidade emocional das famílias que, segundo as professoras, afetam os processos de aprendizagem das crianças. Eis a fala de uma das suas professoras que expressa esta visão:

-Problemas familiares influenciam muito, eu acho, a vida das crianças, seus estudos. Os pais se separam, cada um vai para um lado. Uma criança fica com o pai, a outra com a mãe. $\bigcirc$ pai não quer que ela vá para a escola, a mãe não está interessada nela... eles, muitas vezes, tiram a criança da escola para pedir esmola na rua, como é o caso de uma menina que eu tenho [...]

Os achados referentes às explicações sobre o insucesso escolar, pelas professoras de $A F$, assemelham-se aos obtidos por Rosenholtz (1991) ao investigar as chamadas escolas "pobres em aprendizagem", onde o rendimento dos estudantes era baixo. Nessas escolas, as características pessoais e familiares dos estudantes eram freqüentemente relacionadas às suas dificuldades de aprendizagem. Segundo esta autora, as professoras de tais escolas consideravam um alívio poder culpar as crianças e suas famílias pelo fracasso acadêmico enquanto se isentavam de examinar os problemas de suas próprias práticas.

fato de colocar a responsabilidade do fracasso nas crianças e em suas famílias possivelmente levou as professoras de AF a pensar que havia pouca coisa que poderiam fazer para melhorar o desempenho de seus estudantes. Esta atitude parece ter promovido o clima de total aceitação da pesquisadora encontrado nesta escola. $\bigcirc$ trabalho de investigação foi muito bem recebido em $A F$ enquanto que, 
em BF, duas professoras recusaram-se a ser observadas e houve diversos tipos de pequenos boicotes ao trabalho da pesquisadora (deixaram de notificar a aplicação de algumas provas e a realização de algumas reuniões, por exemplo).

As comunidades atendidas pelas duas escolas eram similares em diversos aspectos, como já foi relatado anteriormente. No entanto, houve um achado que se considerou surpreendente, já que contradizia os resultados do estudo de correlação realizado em Pelotas e de outros estudos realizados fora do país ${ }^{11}$ : as famílias dos estudantes da escola com maior índice de fracasso tinham, em média, um nível de escolaridade maior do que aquele das famílias dos estudantes da escola com menor índice de fracasso. Como a escolaridade está associada ao nível de renda familiar, isso poderia estar indicando que o nível socioeconômico de AF era mais alto do que o de BF. As professoras de AF, entretanto, afirmavam que a maioria de seus estudantes era proveniente de lares "muito carentes", talvez pela existência de um pequeno grupo de famílias muito pobres que freqüentavam esta escola (aproximadamente $10 \%$ do total). As professoras de BF, ao contrário, descreviam as famílias de seus estudantes como pertencendo a níveis de renda "médios", ou como sendo "remediadas".

Como a pobreza e os problemas de ordem emocional dela decorrentes eram vistos como os principais fatores que levam ao fracasso escolar, pelas profes- soras, é possível supor que as que trabalhavam em AF esperassem que seus estudantes apresentassem um desempenho pobre. Esta expectativa era, provavelmente, transmitida aos estudantes através do discurso predominante - o regulativo - que enfatizava os aspectos assistenciais em detrimento dos acadêmicos. Desse modo, os estudantes de AF construíam sua identidade como pessoas que estavam fadadas a não ter uma participação significativa no sistema educacional. Os objetivos que prevaleciam nesta escola eram os de ensinar às crianças as habilidades escolares básicas e de socializá-las de acordo com os valores e os comportamentos-padrão da sociedade, impedindo, ao mesmo tempo, que ficassem abandonadas nas ruas. $O$ acesso ao conhecimento sistematizado, acumulado pela sociedade, o acesso aos princípios mais abstratos que organizam tal conhecimento e o progresso do estudante dentro do sistema educacional não eram metas importantes a ser atingidas através da escolarização em AF.

Em BF, as professoras esperavam que os estudantes fossem bem sucedidos, já que eram percebidos como pertencentes a grupos sociais que apresentam essa possibilidade. Esta expectativa de sucesso criava uma cultura organizada em torno do discurso instrucional, oposta à cultura socializante de AF. A cultura instrucional permitia que um maior número de estudantes alcançasse níveis de desempenho adequados para a promoção e permanência no sistema educacional.

\footnotetext{
${ }^{11}$ A maioria dos estudos correlacionais revisados indicava que quanto maior o nível de escolaridade dos pais melhor o desempenho acadêmico de seus filhos (DAVIE; BUTLER; GOLDSTEIN, 1972; BIANCHI, 1984; PSACHAROPOULOS; YANG, 1991; ILON; MOOK, 1991; DAUBER; ALEXANDER; ENTWISLE, 1993; PATRINOS; PSACHAROPOULOS, 1996).
} 
Os dados colhidos, ao serem traduzidos para a linguagem da teoria da atividade de Leontiev, indicam que os motivos da escolarização eram diferentes em cada uma das escolas estudadas. Nesta perspectiva, os sistemas de atividade são as unidades de análise básicas necessárias para que se compreendam comportamentos individuais e coletivos. Cada atividade pode ser examinada a partir de três níveis diferentes: o da atividade geral e de sua força motivacional (motivo); o das ações dirigidas a uma meta (objetivo); e o dos meios através dos quais essas ações são levadas a cabo (condições) (LEONTIEV, 1981 ; WERTSCH; MINICK; ARNS, 1984; GLASSMAN, 1996; RUSSEL, 1997). Diferentes motivos podem ser atingidos através do mesmo tipo de ações e operações, fornecendo uma pista para explicar a diversidade de desempenho encontrada entre as escolas AF e BF. A prática pedagógica, nestas escolas, não diferia tanto a ponto de explicar a grande disparidade encontrada entre suas taxas de fracasso escolar. No entanto, as diferenças de cultura observadas eram significativas e levaram à hipótese de que refletiam diferenças nos motivos da atividade de escolarização predominante em cada escola. Os motivos em AF eram a socialização e a assistência, e o motivo em BF era a instrução.

\section{Conclusão}

A investigação mostrou a importância de estudar o fracasso escolar através de procedimentos metodológicos amplos. Os achados indicam a extrema relevância da abordagem qualitativa, capaz de jogar luz sobre processos intra-escolares que podem, inclusive, modificar, no nível local, o efeito dos fatores de risco calculados no nível populacional. Os estudos de caso desvelaram relações entre os motivos da atividade de escolarização, a estruturação do discurso pedagógico da escola e o desempenho acadêmico de seus estudantes. Os resultados mostraram que uma cultura que enfatiza os aspectos instrucionais da escolarização é mais eficaz na produção do sucesso acadêmico. Este é um dado importante, na medida em que o fracasso escolar implica enorme desperdício humano e econômico em nossa sociedade, como já referido anteriormente.

Apesar de sua importância, o estudo dos motivos da escolarização não é tarefa simples, pois eles não são facilmente identificáveis e necessitam ser inferidos a partir da cultura escolar. É necessário que um maior número de investigações seja realizado para que se possa entender, também, como tais motivos são gerados e como podem ser modificados na luta contra o fracasso escolar. Pode-se pensar que uma das maneiras de influenciar o desenvolvimento de culturas que conduzam ao sucesso seja a discussão dos preconceitos dos professores quanto aos fatores que levam ao fracasso escolar, tanto nos cursos de graduação quanto nos espaços de formação continuada. É necessário que os professores avaliem a influência tanto de suas concepções quanto de suas práticas e o papel representado pelo discurso pedagógico que predomina em suas escolas sobre o desempenho de seus estudantes. 


\section{Referências}

ARROYO, M. Fracasso-sucesso: o peso da cultura escolar e do ordenamento da educação básica. In: ABRAMOWICZ, A.; MOLL, J. (Ed.). Para além do fracasso escolar. São Paulo: Papirus, 1997.

BAKHURST, D. Social memory in Soviet thought. In: DANIELS, H. (Ed.). An introduction to Vygotsky. London: Routledge, 1996.

BERNSTEIN, B. Class, codes and control: the structuring of pedagogic discourse. London: Routledge, 1990. v. 4.

. Class, codes and control: towards a Theory of Educational Transmission. 2nd ed. London: Routledge \& Kegan Paul, 1977. v. 3.

. Codes, modalities and the process of cultural reproduction: a model,. Language in society, Pittsburg, n. 10, p. 327-363, 1981.

Pedagogy, symbolic control and identity: theory, research, critique. London: Taylor \& Francis, 1996.

BEYER, S. Maternal employment and children's academic achievement: parenting styles as mediating variables. Developmental Review, Oxford, v. 15, n. 2, p. 212-53, 1995.

BIANCHI, S. M. Children's progress through school: a research note. Sociology of Education, Washington, v. 31, n. 6, p. 329-48, 1984.

BRANDÃO, Z.; BAETA, A. M. B.; ROCHA, A. D. C. Evasão e repetência no Brasil: a escola em questão. Rio de Janeiro: Achiamé, 1983.

BRASIL. Ministério da Educação. $\bigcirc$ Brasil quer toda criança na escola. Brasília, DF, [1998?]. Disponível em: <http://www.mec.gov.br>. Acesso em: 16 ago. 1998.

COLEMAN, J. S. et al. Equality of educational opportunity. Washington, DC: Government Printing Office, 1966.

DAMIANI, M. F. Academic failure among Primeiro Grau children in Southern Brazil: from extra-school risk factors to intra-school processes. 1998. Tese (Doutorado em Educação)-Institute of Education, University of London, London, 1998.

Pedagogic discourse and academic failure in southern Brazil. In DANIELS, H.; GARNER, P. (Ed.). World Yearbook of Education 1999: inclusive education. London: Koogan Page, 1999. 
DANIELS, H. Pedagogic practices, tacit knowledge and discoursive discrimination: Bernstein and post-Vygotskian research. British Journal of Sociology of Education, London, v.14, n.4, p. 517-32, 1995.

DAUBER, S. L.; ALEXANDER, K. L.; ENTWISLE, D. R. Characteristics of retainees and early precursor of retention in grade: who is held back? Merril-Palmer Quarterly, Baltimore, v. 39, n. 3, p. 326-43, 1993.

DAVICO, M. I. The repeat and drop-out problem: a study in Brazil on the role of the teacher. Prospects, New York, v. 20, n. 1, 107-113, 1990.

DAVIE, R.; BUTLER, N.; GOLDSTEIN, H. From birth to seven: the second report on the National Child Development Study (1958 Cohort). London: Longman, 1972.

EMERSON, C. The outer world and inner speech: Bakhtin, and the internalization of language. In: DANIELS, H. (Ed.). An introduction to Vygotsky. London: Routledge, 1996.

EVANS, P. Children and youths "at risk". In: OECD. Our children at risk. Paris: CERI, 1995.

FORMAN, E.; MINICK, N.; ADDISON STONE, C. (Ed.). Contexts for learning: sociocultural dynamic in children's development. Oxford: Oxford University Press, 1993.

FRIGOTTO, G. A formação e a profissionalização do educador: novos desafios. In: SILVA, T. T.; GENTILI, P. (Ed.). Escola S. A.: quem ganha e quem perde no mercado educacional do neoliberalismo. Brasília, DF: CNTE, 1996.

GAMA, E. M. P. et al. As percepções sobre a causalidade do fracasso escolar no discurso descontente do magistério. Revista Brasileira de Estudos Pedagógicos, Brasília, DF, v. 72, n. 172, p. 356-84, 1991.

GLASSMAN, M. Understanding Vygotsky's motive and goal: an exploration of the work of A. N. Leontiev. Human development, Berkeley, v. 39, n. 6, p. 309-327, 1996.

GOTTFRIED, A. E.; GOTTFRIED, A. W.; BATHURST, K. Maternal employment, family environment, and children's development: infancy through school years. In: GOTTFRIED, A. E.; GOTTFRIED, A. W. (Ed.). Maternal employment and children's development: longitudinal research. London: Plenum, 1988.

GRANTHAM-MCGREGOR, S. Field studies in early nutrition and later achievement. In: DOBBING, J. (Ed.). Early nutrition and later development. London: Academic Press, 1987. 
HASENBALG, C. A.; SILVA, N. V. Raça e oportunidades educacionais no Brasil. Cadernos de Pesquisa, São Paulo, n. 73, p. 5-12, 1990.

ILON, L.; MOOCK, P. School attributes, household characteristics, and demand for schooling: a case-study of rural Peru. International Review of Education, Hamburg, v. 37 , n. 4 , p. $429-451,1991$.

INSTITUTO NACIONAL DE ESTUDOS E PESQUISAS EDUCACIONAIS ANÍSIO TEIXEIRA. SAEB 2003: relatório do Sistema Nacional de Avaliação da Educação Básica. Brasília, DF, [2003] . Disponível em: < http://www.inep.gov.br/basica/saeb/estados 2004.htm>. Acesso em: 25 fev. 2006.

IVIC, I. Reviews: profiles of educators: Lev S. Vygotsky (1896-1934). Prospects, New York, v. 19, n. 3, p. 427-436, 1989.

JENCKS, C. et al. Inequality: a reassessment of the effect of family and schooling in America. New York: Basic Books, 1972.

LEONTIEV, A. Problems of development of the mind. Moscow: Progress Publishers, 1981.

LEONTIEV, A. The problem of activity in the history of Soviet psychology. Voprosy Psikhologii, Moscow, 4: 109-20, 1986.

LERNER, J. V.; GALAMBOS, N. L. The influences of maternal employment across life: the New York longitudinal study. In: GOTTFRIED, A. W. (Ed.). Maternal Employment and Children's Development: longitudinal research. London: Plenum, 1988.

LEVIN, B. Educational responses to poverty. Canadian Journal of Education, Manitoba, v. 20, n. 2, p. $211-24,1995$.

MELLO, G. N. Magistério de $7^{\circ}$. grau: da competência técnica ao compromisso. São Paulo: Cortez, 1985.

MORTIMORE, P. et al. School Matters: the junior years. Wells: Open Books, 1988.

OFFICE FOR STANDARDS IN EDUCATION. The gender divide. London: Her Magesty's Stationary, 1996.

PATRINOS, A. A.; PSACHAROPOULOS, G. Socioeconomic and ethnic determinants of age-grade distortion in Bolivian and Guatemalan primary schools. International Journal of Educational Development, Bridgetown, v. 16, n. 1, p. 3-14, 1996. 
PENIN, S. A aula: espaço de conhecimento, lugar de cultura. Campinas, SP: Papirus, 1994.

POLLIT, E. Malnutrition and infection in the classroom. Paris: Unesco, 1990.

PSACHAROPOULOS, G.; YANG, H. Educational attainment among Venezuelan youth: an analysis of its determinants. International Journal of Educational Development, Bridgetown, v. 11, n. 4, p. 289-294, 1991.

REYNOLDS, D. School effectiveness and school improvement: an updated review of the British literature. In: REYNOLDS, D.; CUTTANCE, P. (Ed.). School effectiveness: research, policy and practice. London: Cassel, 1992.

ROSENHOLTZ, S. J. Teachers' Workplace: the social organization of schools. New York: Teachers' College Press, 1991.

RUSSELL, D. R. Rethinking genre in school and society: an activity theory analysis. Written Communication, London, n. 14, p. 504-554, 1997. Disponível em:

<http://www.public.iastate.edu/ drrussel/drresume.html>. Acesso em: 4 set. 2000.

SAMMONS, P.; HILLMAN, J.; MORTIMORE, P. Key characteristics of effective schools: a review of school effectiveness research. London: Office for Standards in Education, 1995.

SCHEERENS, J. Basic school effectiveness research: items for a research agenda. School Effectiveness and School Improvement, London, v. 4, n. 1, p. 17-36, 1993.

SCHNEIDER, B.; COLEMAN, J. Parents, their children and schools. San Francisco: Westview, 1993.

STOLL, L.; FINK, D. Changing our schools. Buckingham: Open University Press, 1996.

TOMLISON, S. Ethnic minorities in British schools: a review of literature, 1960-82.

London: Heinemann Educational Books, 1983.

UNICEF. The progress of nations. Oxon: P\& LA, 1995.

VERHINE, R.; MELO, A. M. P. Causes of school failure: the case of the state of Bahia in Brazil, Prospects, New York, v. 18, n. 4, p. 557-568, 1988.

VICTORA, C. G.; BARROS F. C.; VAUGHAN, J. P. Epidemiologia da desigualdade: um estudo longitudinal de 6.000 crianças brasileiras. São Paulo: Hucitec, 1998.

VOLOSINOV, V. Marxism and the philosophy of language. London: Seminar Press, 1973. 
VYGOTSKY, L. S. Mind in society. Cambridge: Harvard University Press, 1978.

WAXMAN, H.; PADRON, Y. Improving the quality of classroom instruction for students at risk on failure in urban schools, Peabody Journal of Education, Nashville, v. 70, n. 2, p. 44-65, 1995.

WERTSCH, J. Voices of the mind: a sociocultural approach to mediated action. London: Harvester Wheatsheaf, 1991.

. Vygostky and the social formation of mind. Cambridge, MA: Harvard University Press, 1985.

WERTSCH, J.; MINICK, N.; ARNS, F. The creation of context in joint problem-solving. In: ROGOFF, B.; LAVE, J. (Ed.). Everyday cognition: its development in social context.

Cambridge: Harvard University Press, 1984.

WOLFF, L.; SCHIEFELBEIN, E.; VALENZUELA, J. Improving the quality of primary education in Latin America and the Caribbean. Washington DC: The World Bank, 1994.

Recebido: 27/09/2006

Aceito para publicação: 30/10/2006 